\title{
Towards Using an E-learning Hybrid model of IS Success and Open Innovation Through an International Innovative Collaboration Environment in Iraqi Universities
}

\author{
Mohamed Ali Mahmod, Asma Binti Md. Ali, Abd. Rahman Bin Ahlan, Asadullah Shah and Muhamad Abu Seman \\ Dept. of Information Systems, International Islamic University Malaysia, Kuala Lumpur, Malaysia \\ mmashadani@gmail.com, Sis_asma@iium.edu.my, \\ arahman@iium.edu.my, asadullah@iium.edu.my, msadri@iium.edu.my
}

\begin{abstract}
Electronic Learning (e-learning) is an inventive approach to offer education using electronic means of learning contents. E-learning is an online education or distance education, which means that it can deliver education to everyone around the world online through the electronic means such as the internet from different distant countries. The success of E-learning process in universities needs to some factors that should be fit with the revolution of technology and enhance the learner's knowledge. In order to adapt the rapid growth of technology, Universities in Iraq needs to collaborate with other international universities and industries to develop e-learning tools and methods. In addition to that, Iraqi universities have to adopt collaboration culture with other universities and industries and adhocracy culture to follow the innovation in e-learning process. This paper suggests a framework that could contribute to enhancing and success e-learning in Baghdad. The IS success model of DeLone and McLean and the open innovation model will be the essential in our developed e-learning framework. The developed framework relies on adopting a collaborative and innovative cultures among universities to promote the e-learning process in universities in Baghdad and Iraq.
\end{abstract}

Keywords—e-learning, collaboration, open innovation, Information System (IS), MOOC.

\section{INTRODUCTION}

Nowadays, e-learning courses and services have become so common in colleges and universities around the world. The main goal of offering the international universities e-learning courses and services is to promote the performance of the education process in general, and to enhance the transferring of the knowledge processes. To acquire and transfer the knowledge, technology could contribute to achieve that and to accomplish the goals of the education process [1].

The joint innovative projects due to the collaboration among universities in e-learning could add more values to the e-learning process in Iraq.

However, on the other hand, Open innovation (OI) is the way toward managing of the cooperation and collaboration with other partners to convey new solutions [2]. Ol comprises of fundamental five stages which are a cultural adaptation, gathering thoughts, screening thoughts, collaborating with resources from outside and make a learning base [2]

The ministry of higher education and scientific research in Iraq followed a strategy to tackle the obstacles which faced e-learning in Iraq by offering a workshop to e-learning units in each university under the supervision of the e-learning unit in the ministry which supervises on each university in Iraq. There are Avicenna centres for e-learning in some universities such as the university of Baghdad and the university of Mustansiriyah in Baghdad. This strategy extended to include offering some staff training workshops due to their international experiences which were a result of their study abroad the country and collaborating with other international universities to follow advancing in technology in e-learning [3]. The strategy of e-learning in the university of Mustansiriyah located in Baghdad is contributing to making Learning Management Systems (LMS) available to enhancing e-curriculum and allow to more students to register and learn. This aim of this strategy is to improve the education process output through employing or investing new techniques in ICT facilities through collaborating with other international universities to support the teaching and learning process such as offering shared innovative e-learning services to the students.

The main objectives of this paper were:

1) to examine the IT capability of the learner effects on the electronic learning process in public universities in Baghdad,

2) to evaluate the impacts of university's collaborative and innovative cultures and its role in succeeding of elearning in public universities in Baghdad, 3) to investigate the effects of the Open innovation 
processes and online courses and their potential roles to success of the e-learning in Iraq,

4) to develop a practical e-learning framework that could add values to the e-learning systems in universities in Iraq.

\section{LITERATURE REVIEW}

A. Previous studies on e-learning Information System success model

Delone and McLean put an essential reference model to the improvement process of the Information Systems in 1992, and they called it "IS success model".

In 2003, Delone and McLean refreshed their model to wind up comprised of six variables which are quality of service, quality of content, quality of system, using of system, satisfaction of the customer and net benefit. Figure 2 illustrates the updated IS success model (2003).

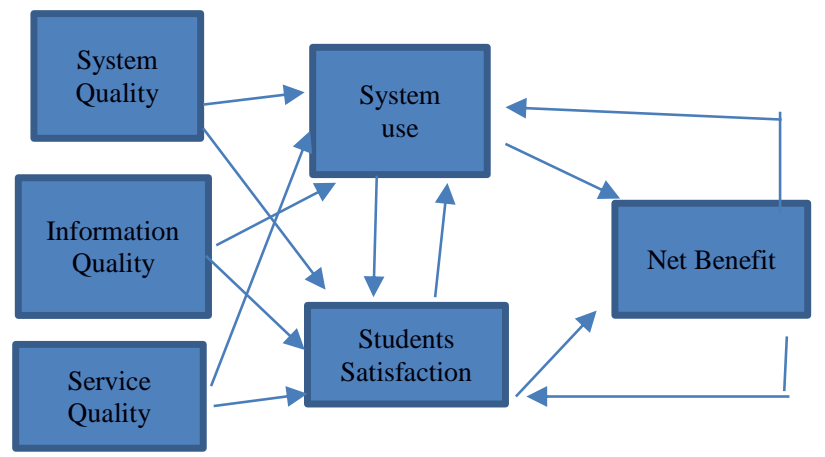

Figure2: IS success model (2003) [4]

For the purpose of forming an e-learning success model, IS success model will be used for e-learning [4]. The previous studies did not consider the individual effect of the student and also the capabilities of the developing countries which relates to the individual technological. In addition, they also did not take into their account the university impact. Increasing the ease of treatment and communication and improving the coordination could enhance the role of the organizational university impact in improving the e-learning process [5].

In order to create a collaborative e-learning environment, the cooperation and collaboration between universities could contribute to share learning events or exchanging ideas in discussions. Jakobus Smit et al [6] described in their research project the role of the organizational culture in promoting information systems management, and they consider in their model the coordination and relationships as main factors of the organizational culture.

It was found that the effects of the organizational culture on information system success, including isolation versus collaboration, centralized versus. decentralized control, internal or external focus and others. They found that collaboration-oriented culture is more feasible use with the implementation of the Information Systems. furthermore, they found that oriented internal culture and the inclination to use of information from outside requires information system use and implementation [7].

\section{B. previous studies on open innovation model}

Open innovation plays an important role in adding values and enhancement to the e-learning process [8]. the collaboration among universities could help in developing of new knowledge depending on the Open Innovation processes.

In order to integrate external information perfectly, the Open Innovation steps are inevitable process which could enable organizations to achieve that. Open innovation is a modern pattern of collaborating and cooperating with the external environment of an organization. The open innovation role in e-learning can be represented by modifying or adapting current curricula at universities in cooperation with other universities and companies, considering particular collaboration and open innovation requirements [9].

Universities should develop its capabilities to ensure making use of external knowledge, ideas and resources. Universities-based research knowledge requires additional investment by businesses in building collaborative networks with external scientists and internal research expertise [10]. Friedman and Angelus [11] defined Open Innovation as "the process of managing the interaction and collaboration of multiple partners to deliver new solutions".

Open Innovation model composed of fundamental stages which are a cultural adaptation, collecting thoughts, sifting thoughts, collaborating with external parties and make a learning basis [12].

The previous studies about using IS success model in the aspect of developing of the e-learning process have concentrated on just the qualities of e-learning system, services and content and its use and user satisfaction without focusing on how to develop it and which means and resources that could be more feasible to achieve the elearning process goals.

However, on the other hand, the previous studies about using open innovation model have focused on the industry like small and medium enterprises without concentrating on the academic field.

This paper will combine both of IS success model and open innovation model to develop the e-learning processes through benefiting from open innovation by using external ideas and resources with the internal resources together such as using external shared e-learning services like MOOCs with the learning management systems (LMS) like 
Moodle, which could enhance the qualities of the system and contents and adding values to the quality of the offered services.

\section{OTHER FACTORS CONTRIBUTING TO ENHANCING THE E-LEARNING PROCESS IN IRAQ}

Another important modern factor that could participate in bringing the revolt to the e-learning process is Massive Open Online Course (MOOC). MOOCs are defined words by words as that "The term "Massive" refers to an educational institution such as universities offering courses registering a lot of students. "Open" means these courses are free to access for anybody in the world. "Online" indicates this is a form of e-learning and learners needs to study via the internet. The courses are taught via digital forms of media, not through paper books or face-to-face lectures. "Courses" means the learning content provided is not fragmented knowledge, but a course which is integrated and designed for learning gradually to cater learners needs and their various levels of perception" [13].

In European countries, universities tend to promote the international collaboration with other universities and industries, and tend to research the predictable effect of Massive Open Online Courses (MOOC) on globalization [14]. In Malaysia, twenty public universities collaborated between each other to offer Malaysia MOOC [15]. The MOOCs in the Islamic International University Malaysia (IIUMs) could be regarded as the expansion to its elearning initiative portal “ITa'leem" [16].

IV. PUTTING ALL TOGETHER: A PROPOSED E-LEARNING FRAMEWORK FOR UNIVERSITIES IN IRAQ

In our proposed framework, we classify factors to independent variables, mediating variables and dependent variables.

The independent variables can be illustrated as the following:

A. student infrastructure capability

1- Computer ownership and self-efficacy: the profession level of students in using their personal computer for study and other activities [17].

2- Accessing of the Internet: this indicates to the student's ability to ensure having internet connection and accessing the websites [19].

B. Service Quality: This refers to the support correlated with the IT units. These qualities of service should ensure accuracy, and reliability of the offered services. Personal skills, capabilities and experience should be involved with the service quality [20].

C. System Quality: to ensure the quality of the system, flexibility, reliability, availability, easiness of learning, ease of use as well usability and response rate should be available [21].

D. Information and Course Content Quality: This indicates to content, services and features offered on the website. To ensure the quality of the curricula, the information and course content must be relevant to the student, accurate and reliable [22].

E. Open Innovation: Open innovation is the is the way toward managing of the cooperation and collaboration with other partners to convey new solutions [23] While the Mediating variables can be demonstrated as the following:

A. Shared e-learning services: This indicates to the elearning services shared among collaborated universities and institutions in the field of elearning such as using cloud computing with learning management system (LMS) which it is considered as the most breathtaking collection of LMS [25], and Massive Open Online Courses (MOOCs).

B. The organizational culture

The organizational culture fundamental functions can be noted clearly in enhancing the sociable system in the organization, and solving problems of internal integration and external acclimation successfully [26].

However, the collaboration between universities together and between it and industries is considered one of the most important cultures of universities that could participate to enhancing universities e-learning processes. It was found that the collaboration between universities, companies and research institutes in computer science domain could add more important values of the learning process through offering new syllabuses, new curricula, and various methods of learning and teaching [27]. The collaborative e-learning is considered an inevitable need for learning organization kind. Developing a collaborative culture of knowledge sharing could play a crucial role in succeeding the e-learning process [28]. sharing ideas and resources, and constructing a general agreement among collaborated members are considered as the essential matters for the collaboration process in e-learning [29].

The collaborated Universities between each other in doing joint projects have a shared sight to promote the e-learning. Dividing into effective multi professional teamwork could participate to perform the shared sight among the collaborated universities [30]. The e-learning process could be promoted through depending on the international 
collaboration between universities and industries together from different countries, which could lead toward performing joint innovative international projects in e-learning field. This study will focus on benefiting from using collaborative and adhocracy (innovative) cultures among universities together and between it and industries as will research the organizational culture influence on the net achievements of electronic learning.

And the dependent variables which we put it under "net Achievements" variable composed of System Use, User Satisfaction, and Net benefit can be defined as the following:

A- System use: This indicates to the method and trend of using the system by students [31].

B- Student satisfaction: This refers to which student is satisfied with the system and its offered services and whether this e-learning system cater student's needs.

C- Net benefits: This indicates to the extent to which elearning system contributes to improve student knowledge, improved productivity, cost reduction and save time [32], making external and internal mutual projects and benefiting from new ideas and resolving e-learning-related issues. might ensure continuous enhancement for the e-learning system and the entire e-learning process.

study will use a combination of IS success model and Ol model together in order to identify the most feasible elements which could participate to enhance and adding values to the e-learning systems in public Iraqi universities. Therefore, this study determined some gaps in literature review such as poor previous research on the e-learning success, lack of concentration given to the participating elements of e-learning process using the IS success factors, the benefiting from the Open Innovation process in elearning, and the lack of focus on the importance of the individual learner's elements, organizational (university) impact and culture in succeeding of e-learning. This study seeks to address these gaps. Figure 3 illustrated the integrated developed framework of this paper.

\section{DATA COLLECTION AND ANALYSIS}

This paper employed mixed of both quantitative and qualitative study design in which data were collected from students in four public universities in Baghdad. Questionnaire was submitted to a total of 293 participants of students. Meantime, stratified sampling is used base on university name and department name. Choosing the sample depending on two departments out of other departments in all these 4 universities with the size of 2000 requires cluster sampling to achieve that. The random sampling is the suitable method for the targeted departments which are computer engineering and computer science.

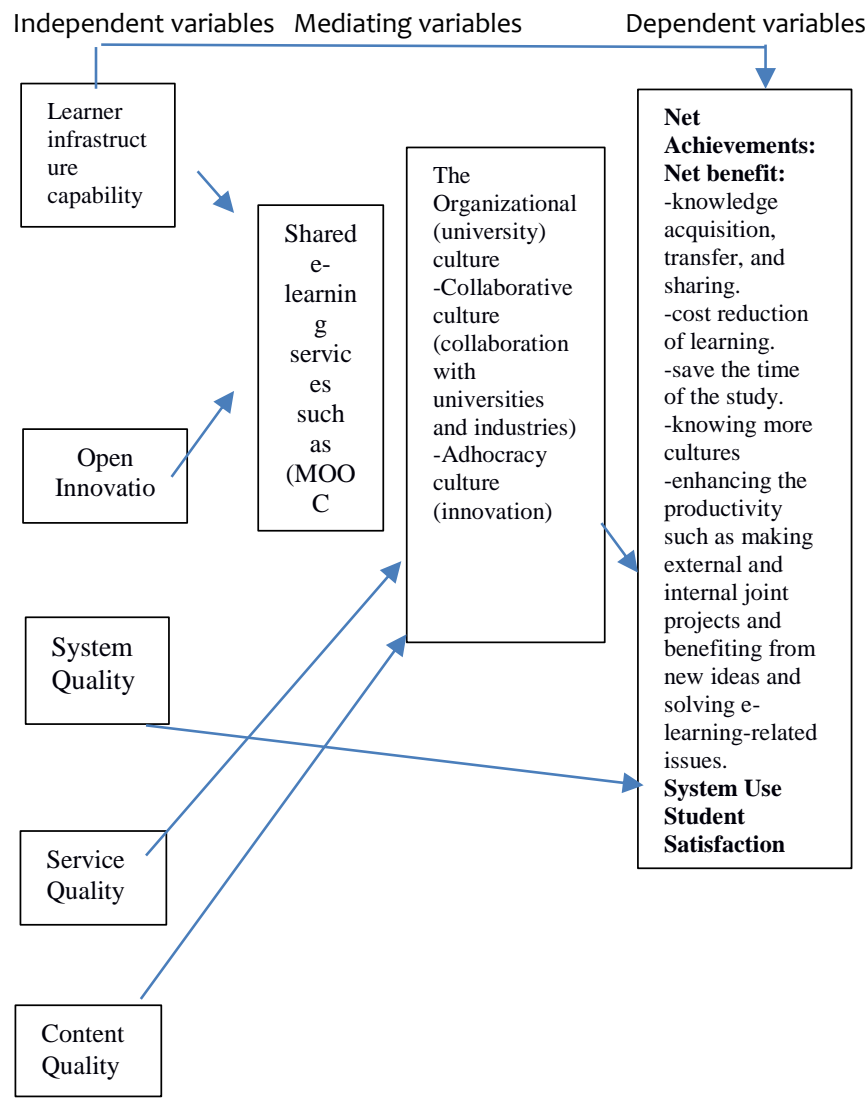

Figure 1: The developed research framework

\section{RESULTS}

Hooper, Couphlan and Mullen (2008) suggested reporting Chi-Square Test (X2), degree of freedom (df), $\mathrm{p}$ value, Root Mean Square Error of Approximation (RMSEA), Comparative Fix Index (CFI) and parsimony fit index such as the PNFI having cut-offs of RMSEA $<0.1$ is acceptable and best $<0.08, \mathrm{CFI}>0.9$ is good while $>0.95$ is best, Normed Chi-Square $\left(\mathrm{X}_{2} / \mathrm{df}\right)<5$. While, Hair et al. (2006) indicated that the critical ratio value had to be more than 1.96. The results of examining the proposed framework quantitively determine which hypothesis are positive or significant and which are not significant through measuring the Confirmatory Factor Analysis (CFA). It is clear that the open innovation model added value to the proposed framework of Is success model where each of the open innovation, MOOC, and the organizational university culture enhanced the IS success model through adding more good results to it. Figure 3, 4 and 5 demonstrate the good results of the CFA for the open innovation paradigm, MOOC, and the organizational university culture 


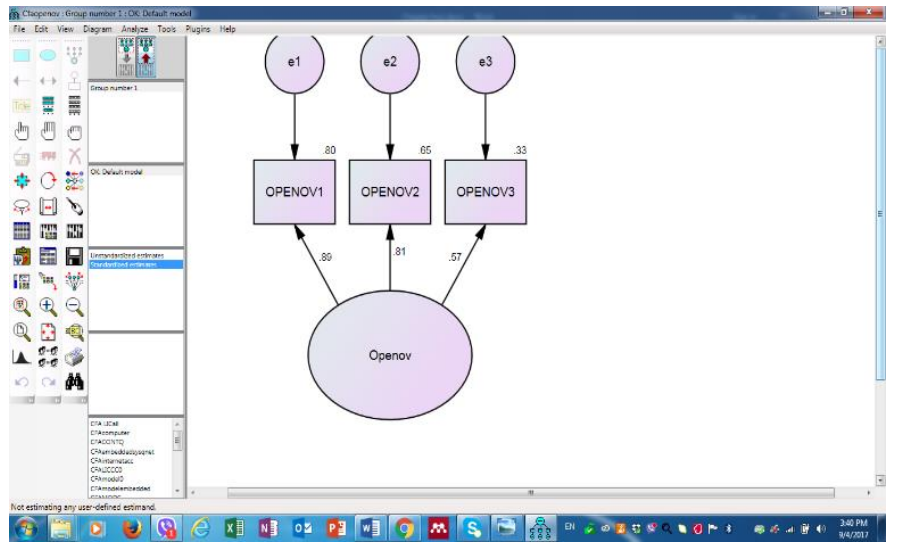

Figure 4: CFA of the Open Innovation

The model fits results are shown, indicating a good model fit to data $\left(X^{2}=1.456, d f=2, p=0.460, X^{2} / d f=0.728, C F I=\right.$ 1.000, RMSEA $=0.000$.

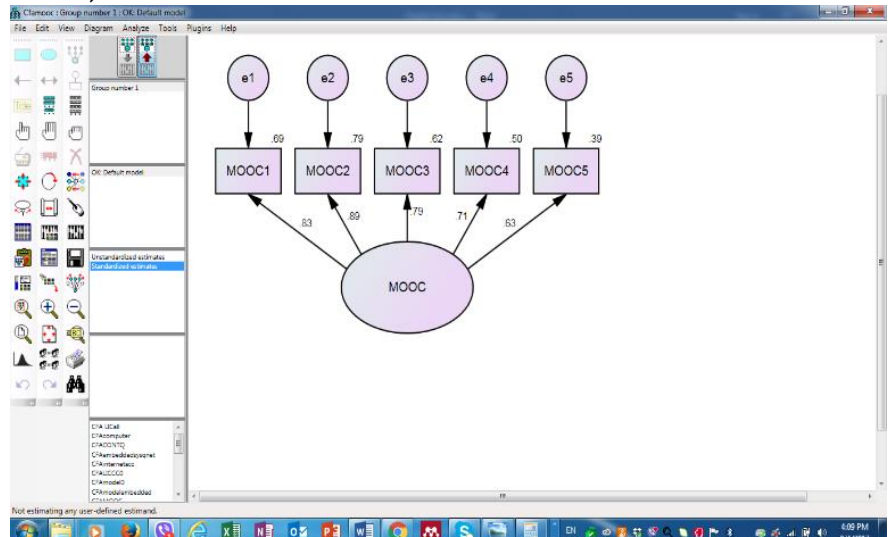

Figure 5: CFA of the MOOC

The model fits results are shown, indicating a good model fit to data $\left(X^{2}=18.254, \mathrm{df}=5, X^{2} / \mathrm{df}=3.65, \mathrm{CFI}=0.998\right.$, RMSEA $=0.094$.

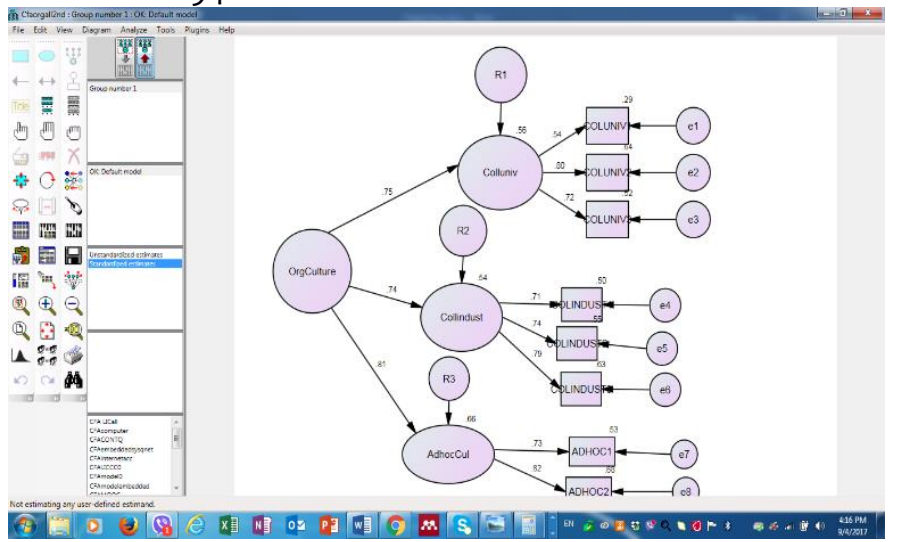

Figure 6: CFA of the Organizational University Culture

The model fits results are shown, indicating a good model fit to data $\left(X^{2}=57.821, d f=17, p=0.000, X^{2} / d f=3.40, C F I=\right.$ 0.947 , RMSEA $=0.074)$.

It is found that the proposed framework composed of two hybrid models IS success model and Open Innovation model contributes to enhancing IS success model of the e- learning process in universities in Baghdad. Figures 7, 8, 9, 10 and 11 illustrate the good results of the structural model composed of the open innovation, MOOC, organizational university culture and net achievements composed of net benefits, system use, and user satisfaction. In figure 7, the result of the critical ration of this model are above 1.96, it is 4.77.

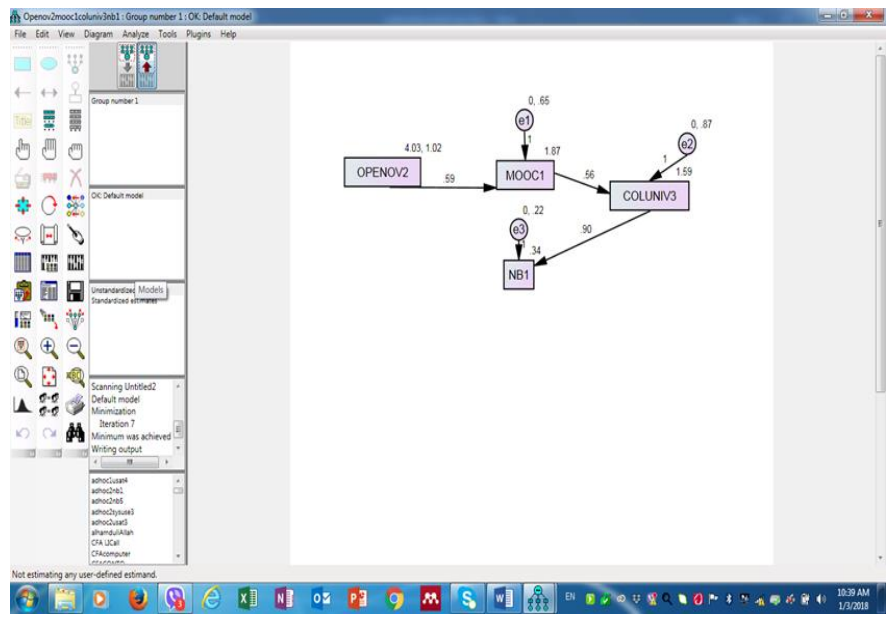

Figure 7: The structural model of OI, MOOC, UC (Colluniv), and NB

In figure 8 , the result of the critical ration of this model is above 1.96 , it is 3.68 .

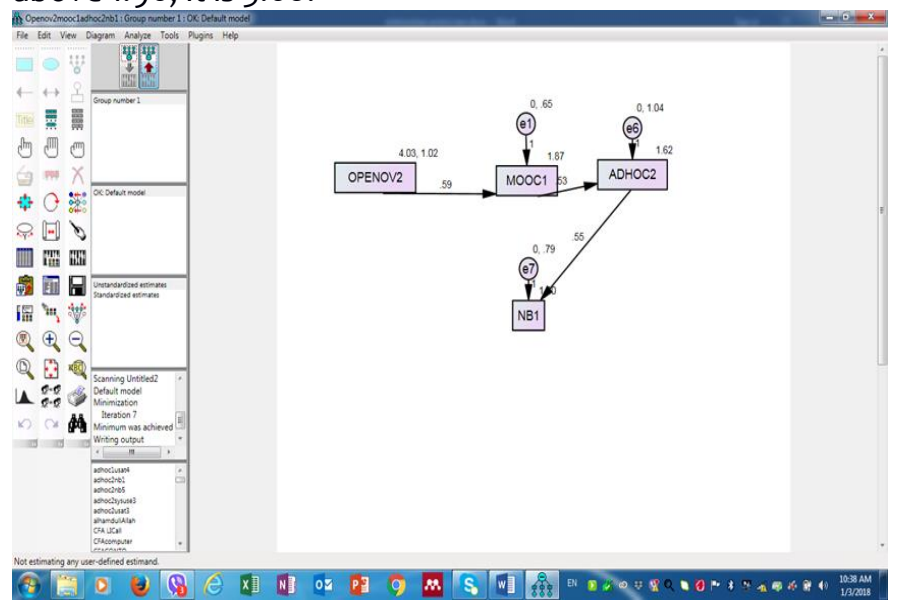

Figure 8: The structural model of OI, MOOC, UC (Adhoc) and NB

In figure 9, the result of the critical ratio of this model is above 1.96 , it is 5.93 . 


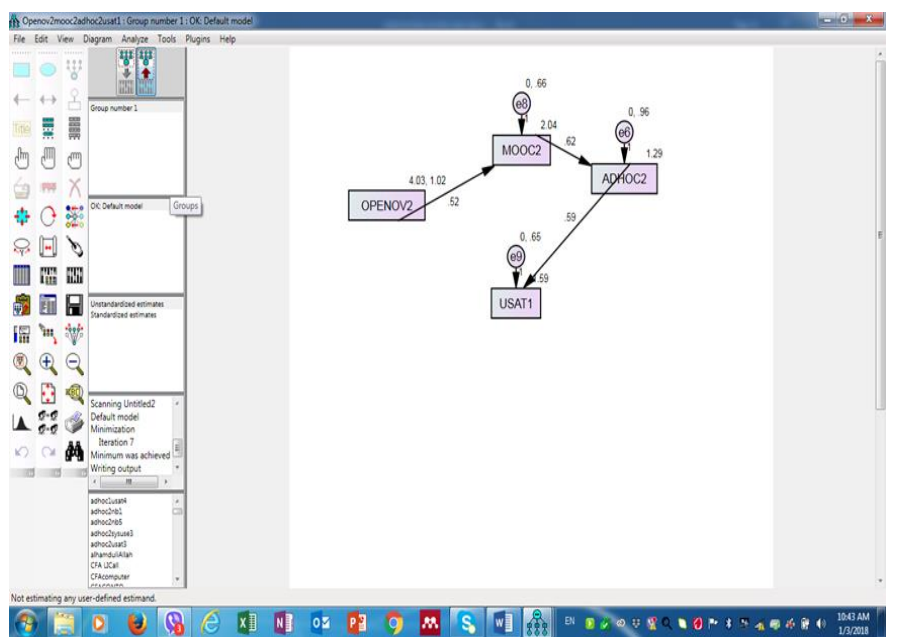

Figure 9: The structural model of OI, MOOC, UC (Adhoc), and USAT

In figure 10, the result of the critical ratio of this model composed of OI, MOOC, COLLUNIV, and SYSUSE are above than 1.96 , it is 3.07 .

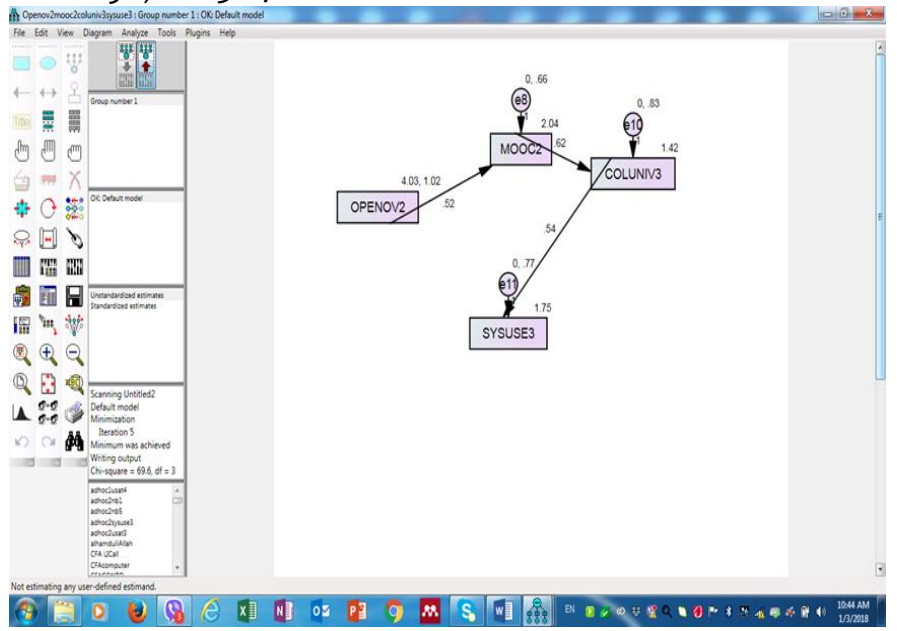

Figure 10: The structural model of OI, MOOC, COLLUNIV, and SYSUSE

In Figure 11, the result of this model composed of OI, MOOC, COLLUNIV, and USAT is above than 1.96, it is 7.40 .

\section{REFERENCES}

[1] Haythornthwaite and Andrews, "Elearning theory and practice". Sage publications Inc: London, 2011.

[2] M. Roshani, M. Roshani, N. Lehoux, and J. Frayret, "University-Industry Collaborations and Open Innovations: An Integrated Methodology for Mutually Beneficial Relationships University-Industry Collaborations And Open Innovations: An Integrated Methodology for Mutually Beneficial Relationships," no. June 2015.

[3] Ministry of Higher education and Scientific research in Iraq, 2015.

[4] S. Petter, W. DeLone, and E. McLean, "Measuring information systems success: models, dimensions, measures, and interrelationships," Eur. J. Inf. Syst., vol. 17, no. 3, pp. 236-263, 2008.

[5] A. Kamel, D. Lakhder, and Z. Ammar, British Journal of Arts and Social Sciences, ISSN: 2046-9578, Vol.9, No. 2, 2012.

[6] S. Jakobus; Dellemijn, Marielle; and Silvius, Gilbert, "The Relationship
Between Organizational Culture, Information Systems, Management and Change Readiness". PACIS, pp. 143, 2012

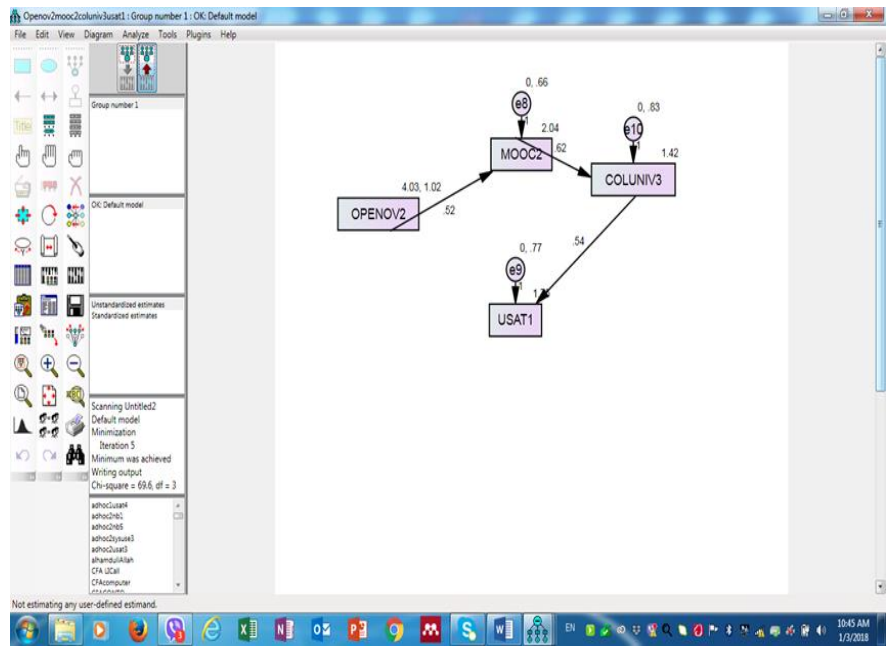

Figure 11: The structural model of OI, MOOC, COLLUNIV and USAT

In addition to that, it was found that there are some factors are not significant and some of them does not work when we use IS success model only. So, the using of Open innovation model together with the IS success model promoted the integrated framework of the e-learning process in public universities in Baghdad.

\section{CONCLUSION}

This paper determined the main factors which could contribute to e-learning success in universities in Iraq. In addition to that, this paper proposed an integrated framework of e-learning which links the individual impact with the organizational impact. The proposed framework consists of hybrid models of both IS success model and open innovation model. The results confirmed that using the open innovation model together with the IS success model could enhance the e-learning process in public universities in Baghdad.

[7] S. Wang, N. Archer, Y. Pei, “In IFJP International Federation for In Coronation Processing”. Volume 254, Research and Practical Issues of Enterprise Information Systems II Volume I. cds. L Xu. Tjoa A.. Chaudhry S. (Boston: Springer). pp. 617-626, 2007.

[8] B. Kux, "Universities and Open Innovation: a new research paradigm”,2008.

[9] EURIS, “Embracing OPEN INNOVATION IN EUROPE: A Best Practices Guide on Open Innovation Policies euris project”, 2012.

[10] K. R. Fabrizio, "The use of university research in firm innovation", Chesbrough, H.W., Vanhverbeke, W. and West, J. (Eds), Open Innovation: Researching a New Paradigm, Oxford University Press, Oxford, pp. 134-61, 2006.

[11] M. Freeman and E. T. Al, "The impact of individual philosophies of teamwork on multi-professional practice and the implications for education," 2000.

[12] M. Roshani, M. Roshani, N. Lehoux, and J. Frayret, 
"University-Industry Collaborations and Open Innovations: An Integrated Methodology for Mutually Beneficial Relationships University-Industry Collaborations and Open Innovations: An Integrated Methodology for Mutually Beneficial Relationships," no. June 2015

[13] S. Wang, “From e-learning to Mooc”, vol. 9, pp. 35-42, 2014.

[14] M. Gaebel, "MOOCs Massive Open Online Courses”, 2014.

[15] Malaysia MOOC, 2016. https://www.openlearning.com/malaysiamoocs

[16] A. B. A Dahlan, S. S. B. Juhari, and A. S. B. A. Shafiee, "MOOCs at International Islamic University Malaysia”, International Journal of Computer Science and Information Technology Research ISSN 2348120X (online) Vol. 3, no. 2, pp. 140-149, June 2015.

[17] J. Burns, "A third of poorest pupils without internet at home", BBC new education and family, 2013.

[18] J. A. Van DIJK, "The evolution of the digital divide the digital divide turns to inequality of skills and usage", 2012.

[19] V. Ndume, F. N. Tilya, and H. Twaakyondo, "Challenges of adaptive elearning at higher learning institutions: a case study in Tanzania", International Journal of Computing and ICT Research, vol. 2, no. 1, 4759, 2008.

[20] A. Leclercq, "The perceptual evaluation of information systems using the construct of user satisfaction: case study of a large French group". the DATABASE for advances in information systems, vol. 38, no. 2, pp. 27-60, 2007.

[21] R. D. Freeze, K. A. Alshare, P. L. Lane, and H. J. Wen, "IS success model in e-learning context based on student's perceptions", Journal of Information Systems education, vol. 21, no. 2, pp. 173-184, 2010.
[22] D. Rossin, K. R. Young, D. K. Barbara, and M. G. Yi, "The effects of flow on learning outcomes in an online information management course", Journal of Information Systems Education, vol. 20, no. 1, pp. 87-98, 2008.

[23] M. Friedman, H. Angelous, "Best Practices in Collaborative Innovation How Manufacturers and Retailers Can.”, 2009.

[24] S. Wang, “From e-learning to Mooc," vol. 9, pp. 35-42, 2014.

[25] J. Leh, “MARKET TRENDS," 2017.

[26] R. Ismail, "Organizational Culture Impact on Information Computer Science and Software Techniques in 2011 Organizational Culture Impact on Information Systems Success," no. APRIL 2011, 2016.

[27] G. Sabau, I. Lungu, R. Bologa, and A. R. Bologa, "Information Systems in University Learning," vol. 14, no. 4, pp. 171-182, 2010.

[28] T. Sahama and H. Pillay, "Realisation of University-Industry Collaboration Through Industry-Based Learning At Indonesian Higher Education," no. March, pp. 3853-3863, 2016.

[29] L. L. Ellingson and D. Ph, "Communication, Collaboration, and Teamwork among Health Care Professionals,” vol. 21, no. 3, 2002.

[30] Freeman, et al, "the impact of individual philosophies of team work on multi professional practice and the implications for education, 2000.

[31] L. A. Halawi, R. V. McCarthy and J. E. Aronson, "An empirical investigation of knowledge management systems". The Journal of Computer Information Systems, 2007, pp.121-136.

[32] S. Petter, W. DeLone, and E. McLean, "Measuring information systems success: models, dimensions, measures, and interrelationships," Eur. J. Inf. Syst., vol. 17, no. 3, pp. 236-263, 2008. 